\title{
SYNTHESIS OF BENTONITE NANOCLAY AND INCORPORATION OF CASSIA FISTULA LEAF EXTRACT TO FORM ORGANOBENTONITE: CHARACTERIZATION AND ITS BIOMEDICAL APPLICATIONS
}

\author{
ANAND RAJ LFA*, JESLIN J \\ Department of Biotechnology, St Joseph's College of Engineering, OMR, Chennai, Tamil Nadu, India. Email: anandlfa@yahoo.co.in
} Received: 16 April 2018, Revised and Accepted: 4 June 2018

\section{ABSTRACT}

Objective: In this work, methanolic leaf extract from Cassia fistula (known as aragvadha) was incorporated into bentonite nanoclay to form organobentonite. This organobentonite of nanosize was further used for its effective biomedical applications since medicinal clay finds its own advantage over decades.

Methods: The bentonite nanoclay was produced by energetic stirring followed by centrifugation and was characterized using scanning electron microscopy (SEM), X-ray diffraction (XRD), and Fourier transform infrared (FTIR). The organobentonite was produced using freeze and thaw method. Antioxidant property was studied using Molyneux method, and thrombolytic activity was analyzed using in vitro clot lysis method.

Results: The nanosize of bentonite nanoclay between 57 and $82 \mathrm{~nm}$ with irregular to spherical shape was confirmed using SEM analysis. The sharp diffraction peak in XRD analysis shows the crystalline nature of bentonite nanoclay, and FTIR results revealed the successful incorporation of the methanolic extract within the bentonite nanoclay. The organobentonite exhibits $84.5 \%$ antioxidant property as well as $31 \%$ clot lysis activity when compared to the extract and the bentonite nanoclay.

Conclusion: Thus, the non-toxic and inexpensive bentonite nanoclay have a high aspect ratio with multifarious applications in medicine, food, cosmetics, and health products. Through this study, the bentonite nanoclay modified using plant alkaloid (organobentonite) is found to possess good biomedical property.

Key words: Bentonite, Nanoclay, Organobentonite, Biomedical.

(c) 2018 The Authors. Published by Innovare Academic Sciences Pvt Ltd. This is an open access article under the CC BY license (http://creativecommons. org/licenses/by/4. 0/) DOI: http://dx.doi.org/10.22159/ajpcr.2018.v11i9.26717

\section{INTRODUCTION}

Nanoclay is the new class of nanomaterials belonging to clay minerals, which offers cheap and eco-friendly source for different novel applications [1,2]. In nature, the clay minerals are layered as hydrous silicate sheets, stacked one over the other [1]. Nanoclay can be obtained from clay minerals through various methods such as centrifugation, freeze drying, energetic stirring, cross-flow filtration, or through ultracentrifugation [3]. These methods can delaminate clay minerals into individual sheets which can give a high aspect ratio, at least in one dimension. The synthesis of nanoscale particles without toxic chemicals overcomes the difficulties in its use in biomedical field with enhanced properties and with lesser side effects $[4,5]$.

Bentonite is one of the clay minerals that possess interlayer of silica and alumina. It is naturally formed from volcanic ash weathering in the presence of water. It can be used without any modification or can be modified using certain physiochemical treatments based on their applications [6-8]. It is mainly used in structural polymers, ceramic bodies, drilling fluids [9], and also in adsorption catalytic processes [10]. The incorporation of any molecules within the nanoclay system does not affect the nature of the molecules. When it is modified by the addition of any plant alkaloids, it is known as organobentonite. This incorporation occurs by different molecular interactions such as hydrogen bonding, ion exchange, and dipole interaction [11]. Furthermore, the incorporation of plant extracts into the nanoclay forms a novel nanopackaging system which helps in the storage of compounds in a highly stable form against the environment changes [12].

Cassia fistula (Golden shower tree) is a well-known flowering plant which belongs to the Fabaceae family. This medium sized (33-66 ft), fastgrowing tree is widely distributed in various parts of the world such as
South Africa, Asia, Mexico, Brazil, East Africa, and China. It is commonly found as an ornamental tree with compound leaves containing 4-8 leaf pairs in opposite leaflets and contains bundles of flowers in yellowish color [13]. It is used as an herbal medicine and has a high therapeutic value to treat various diseases such as diabetes, leukoderma, hematemesis, pruritus, and rheumatism. It is also found to exert analgesic, antipyretic, hypoglycemic activity, and anti-inflammatory activity [14]. For treating certain infectious diseases, it is used as a broad-spectrum antimicrobial agent [15]. Hence, in Ayurvedic medicine, it is known as disease killer. The phytochemicals of $C$. fistula are highly target specific, eco-friendly, less resistivity, and high acceptability which makes it efficient for various biomedical applications [16].

With an account of the above advantages, this work was focused on the incorporation of methanolic extract of $C$. fistula leaves into bentonite nanoclay to form organobentonite. The bentonite nanoclay was characterized before and after organobentonite formation and was utilized for its biomedical applications such as antioxidant and thrombolytic activity.

\section{EXPERIMENTAL}

\section{Materials}

Natural bentonite clay was purchased from Jain Lab Chemicals, Chennai. The other chemicals were of analytical grade purchased from Fisher Scientific. C. fistula leaves were collected from our campus and were washed with double-distilled water for further processes.

\section{Characterization techniques}

Ultraviolet (UV)-VIS spectroscopy (SYSTRONICS Double beam UVVIS Spectrophotometer: 2202, scan mode from $200 \mathrm{~nm}$ to $700 \mathrm{~nm}$ ), 
X-ray diffraction (XRD) spectroscopy (using XPERT Pro, PANalytical JDX-8030, and JEOL), scanning electron microscope (Tescan Vega 3 SBU model, $0.005 \mathrm{~Pa}$ to $2000 \mathrm{~Pa}$ ), and Fourier transform-infrared (FTIR) spectroscopy (Perkin Elmer-spectrum one, range of 500-4500 $\mathrm{cm}^{-1}$ ) were used to characterize the nanoclay and organobentonite produced.

\section{Nanoclay preparation}

The bentonite nanoclay was prepared using modified Floody et al. method [17]. In this method, $5 \mathrm{~g}$ of clay was mixed with $100 \mathrm{ml} 1 \mathrm{M} \mathrm{NaCl}$ and ultrasonicated at $4280 \mathrm{~J} \mathrm{~g}^{-1}$ for $5 \mathrm{~min}$. It was then centrifuged at $654 \mathrm{~g}$ for $40 \mathrm{~min}$. The first round of the supernatant contains mineral impurities; hence, it was discarded. The pellet was resuspended in $50 \mathrm{ml}$ deionized water and was subjected to moderate stirring for $40 \mathrm{~min}$. The supernatant was collected by repeating the process for 11 more times and was dried in hot air oven at $60^{\circ} \mathrm{C}$.

\section{Organic matter removal}

The removal of organic matter was necessary to prevent the agglomeration of bentonite nanoclay. For that, $2 \mathrm{mg} / \mathrm{ml}$ suspension concentration on produced nanoclay was treated with $30 \%$ hydrogen peroxide (1:2). The method follows modified James et al. [18]. The above suspension was moderately stirred for $3 \mathrm{~h}$ to form a homogenous mixture. The $\mathrm{pH}$ of the homogenous mixture was neutralized using $0.5 \mathrm{M}$ sodium hydroxide and was again stirred at $100 \mathrm{rpm}$ for $1 \mathrm{~h}$ in a magnetic stirrer. The bentonite nanoclay was then obtained by drying the mixture at $60^{\circ} \mathrm{C}$

\section{Leaf extraction}

The leaves from $C$. fistula were collected and washed with doubledistilled water. It was then shade dried and was powdered using a blender. $5 \mathrm{~g}$ of powdered leaves was mixed with $50 \mathrm{ml}$ methanol (1:10) and was kept in shaker for $48 \mathrm{~h}$. The extract was filtered out using Whatman filter paper No.1 [19].

\section{Formation of organobentonite}

The incorporation of the methanolic extract within the nanoclay was carried out by modified freeze and thaw method [20]. Briefly, $2 \mathrm{~g}$ of the nanoclay produced was mixed with $40 \mathrm{ml}$ of methanolic extract to become a homogenous mixture. The mixture was then frozen at $-20^{\circ} \mathrm{C}$ for $24 \mathrm{~h}$ and was thawed at room temperature.

\section{Antioxidant property}

The antioxidant property was analyzed using Molyneux method [21] using the strong antioxidant, 2,2-diphenyl-2-picrylhydrazyl (DPPH). The method follows dissolving $1.97 \mathrm{mg}$ of DPPH in $50 \mathrm{ml}$ of pure methanol (radical reagent). $60 \mu \mathrm{l}(1 \mathrm{mg} / \mathrm{ml})$ of extract, nanoclay and organobentonite were added to $840 \mu \mathrm{l}$ of DPPH radical reagent and mixed together. The reaction was kept undisturbed in the dark for $15 \mathrm{~min}$ at room temperature. The color change was measured at $517 \mathrm{~nm}$ using UV-Vis spectrophotometer. The percentage of inhibition was found using: \%inhibition $=\left[\left(A_{0}-A_{15}\right) / A_{0}\right] \times 100$; where, $A_{0}=0 D$ for $\mathrm{DPPH}$ and $\mathrm{A}_{15}=\mathrm{OD}$ for sample.

\section{Clot lysis activity}

The thrombolytic activity was studied through in vitro clot lysis method [22] (approved protocol by the Institutional Ethics Committee) in which venous blood was collected from a healthy volunteer with no history of oral contraceptive and anticoagulant therapy. The $500 \mu \mathrm{l}$ of blood was evenly distributed in four preweighed microfuge tubes and incubated for $45 \mathrm{~min}$ at $37^{\circ} \mathrm{C}$ to form clots. The serum found above the clot was removed by pipetting, and the initial clot weight was noted. $100 \mu \mathrm{l}$ of distilled water was added as a control, and other three tubes were added with the $(0.1 \mathrm{mg} / \mathrm{ml})$ extract alone, nanoclay and organobentonite. The tubes were incubated at $37^{\circ} \mathrm{C}$ for $90 \mathrm{~min}$ and the final clot weight was determined using the formulae: Clot weight $=\mathrm{W}_{\text {clot }}-\mathrm{W}_{\text {tube }} ; \mathrm{W}_{\text {clot }}=$ weight of clot containing tube and $\mathrm{W}_{\text {tube }}=$ weight of tube alone, by measuring the weight of the clot before and after lysis.

\section{RESULTS AND DISCUSSION}

\section{UV-Vis spectroscopy}

The organic molecules are known to have maximum absorption peak between 200 and $700 \mathrm{~nm}$. The absorption of light in the UV or visible region of the electromagnetic spectrum gives the ground state to higher energy state electronic transitions due to the high degree of conjugation of molecules. In Fig. 1, the obtained peak at $252 \mathrm{~nm}$ denotes the presence of the conjugated system attributing to $\pi \rightarrow \pi^{*}$ transition of $\mathrm{Si}=0$ functional group. Meanwhile, the peak at $340 \mathrm{~nm}$ denotes the lone pairs of electron on the hydroxyl substituent and alumina conjugation attributing to $n \rightarrow \pi$ transitions. This result was found; moreover, similar to the results obtained by Wanyika et al. [23] for the montmorillonite (MMT) clay since the bentonite has MMT as its major constituent the peaks match to the earlier results.

\section{XRD analysis}

The XRD pattern in Fig. 2 reveals similar results obtained by Venkatathri [10]. The sharp peaks in the pattern infer that the clay is polycrystalline in nature. The diffraction peaks at the angles $25.28^{\circ}, 27.68^{\circ}, 36.94^{\circ}$, $37.80^{\circ}, 38.57^{\circ}, 55.06^{\circ}$, and $62.12^{\circ}$ correspond to the crystal planes of

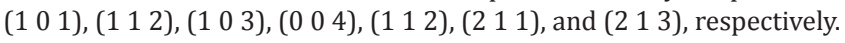
Similarly, the peak at $27.68^{\circ}$ corresponds to MMT.

\section{Scanning electron microscopy (SEM) analysis}

The SEM analysis revealed the nanosize of the produced nanoclay; however, agglomeration of the nanoclay was observed in Fig. 3 before hydrogen peroxide treatment. The agglomeration makes it difficult for the determination of the size of the nanoclay. After the treatment with $30 \%$ hydrogen peroxide, the encrusted and occluded organic matter removal prevented the agglomeration formation such that the produced nanoclay was in irregular to spherical shaped with $57-82 \mathrm{~nm}$ size (Fig. 4).

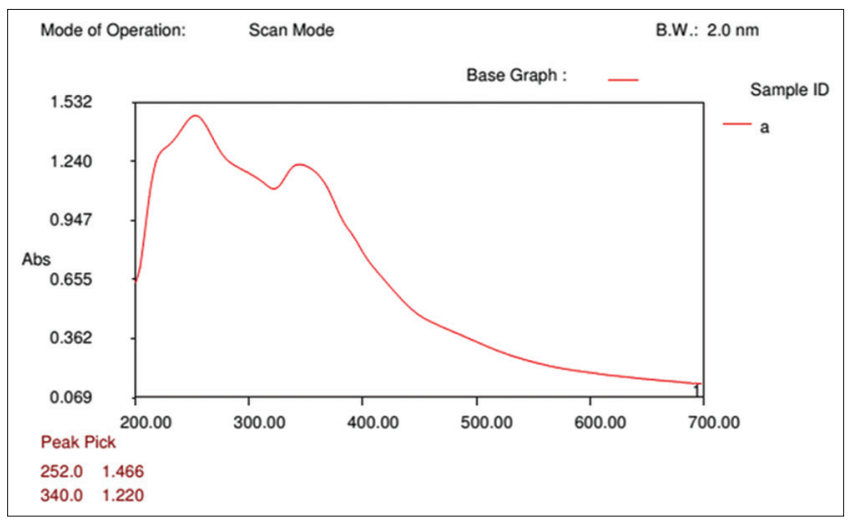

Fig. 1: Ultraviolet-visible spectroscopy analysis of nanoclay

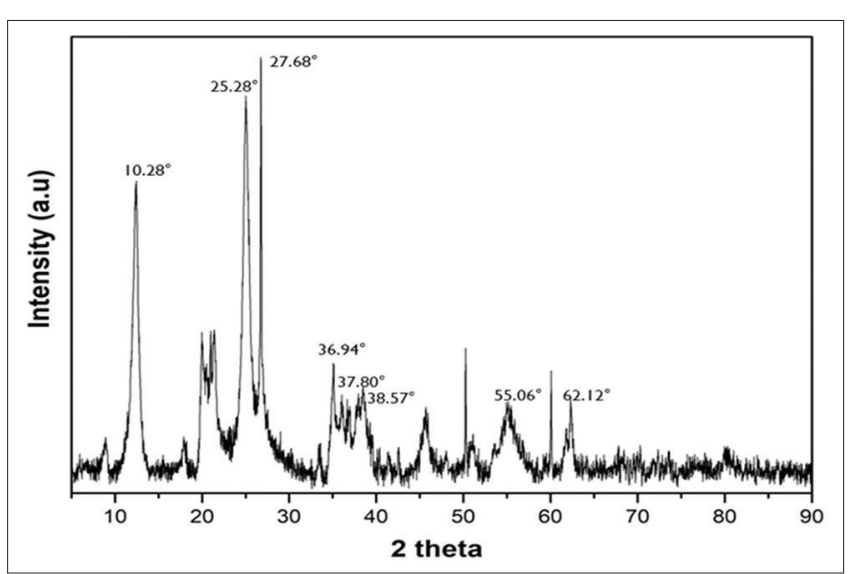

Fig. 2: X-ray diffraction analysis of nanoclay 
FTIR analysis

The peaks at 466,523 , and 797 are due to the pore opening, 920 is due to the double ring formation, while 1045 and $1110(1 / \mathrm{cm})$ in Fig. 5 show the symmetric and asymmetric T-O-T vibrations (where $\mathrm{T}$ is $\mathrm{Al}$ or $\mathrm{Si}$ ) in the bentonite nanoclay. The Si-O-Si vibrations are confirmed by the peak at 881 . The silanol group (Si-OH-Al) in the crystallographic position of nanoclay was confirmed by the prominent peak at $3643 \mathrm{~cm}^{-1}$.

The peaks at $675.09,1023,1242.16,1361.74,2918.30$, and 3277.06 in Fig. 6 denote the presence of alkenes, alcohols, carboxylic acids, nitro compounds, hydrogen bonded alcohols, and phenols as its major phytochemical constituents.

The formation of peaks at 797, 881, 920, and 3643 in Fig. 7 along with the spectrum obtained in the pure extract $(1023,3277$, and 1242.16) without nanoclay reveals that the leaf extract was successfully incorporated with the produced nanoclay.
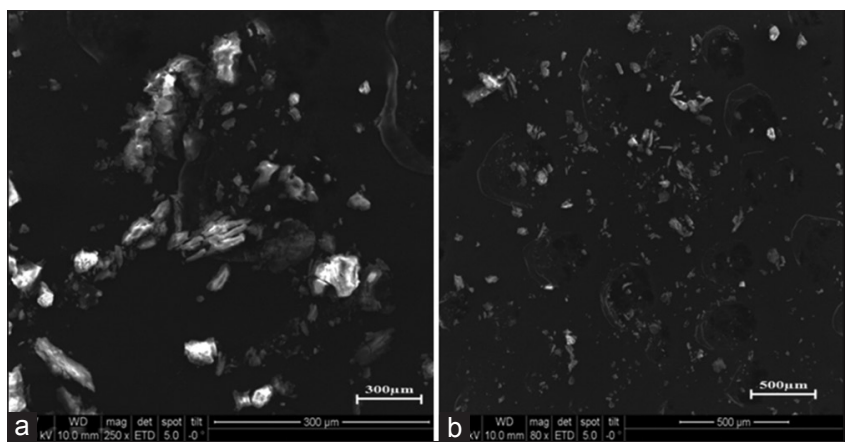

Fig. 3: (a and b) Scanning electron microscopy images of nanoclay before hydrogen peroxide treatment
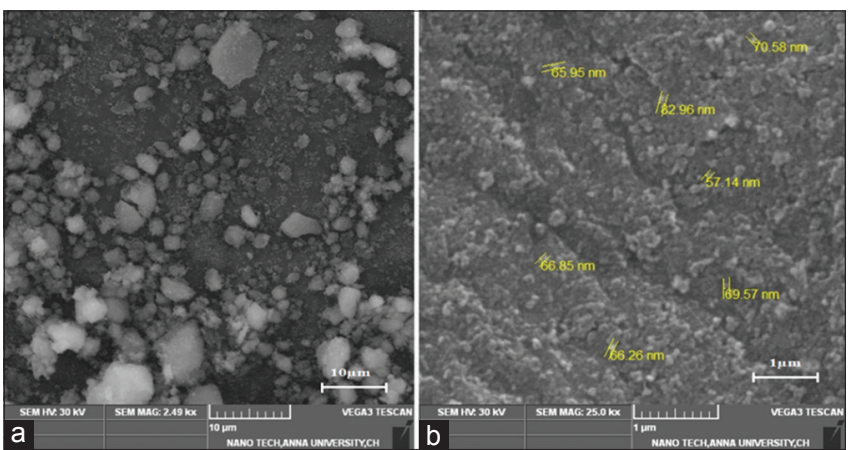

Fig. 4: ( $a$ and b) Scanning electron microscopy images of nanoclay after hydrogen peroxide treatment

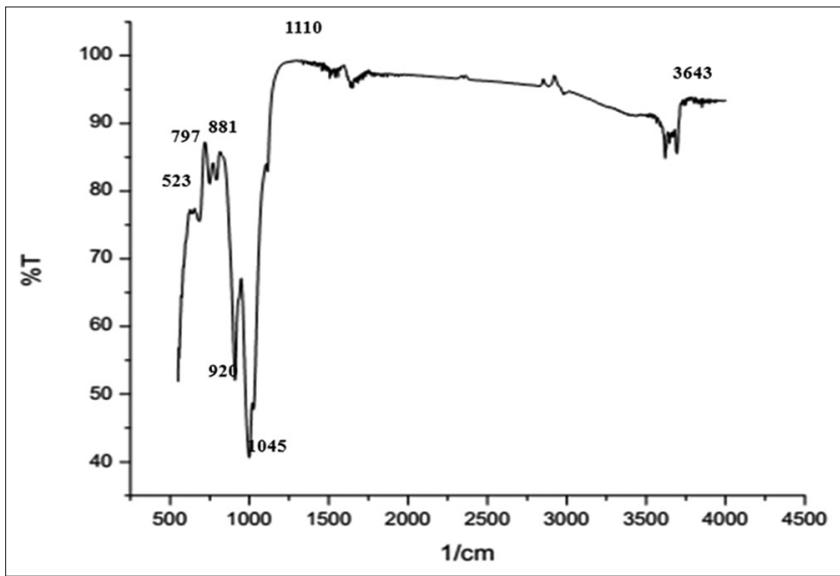

Fig. 5: Fourier transform-infrared analysis for nanoclay
Antioxidant property

The antioxidant property found using Molyneux method in Fig. 8 revealed a color change in the radical reagent from dark pink to pale brownish color in the mixture containing organobentonite as well as for the extract alone. However, the nanoclay alone (Fig. 8a) does not show any drastic change in the color. The absorbance value was also found to decrease for the three mixtures, whereas the (organobentonite) incorporated system showed highest inhibition of $84.5 \%$ than other two. The extract alone has $77 \%$ inhibition; whereas, nanoclay alone has

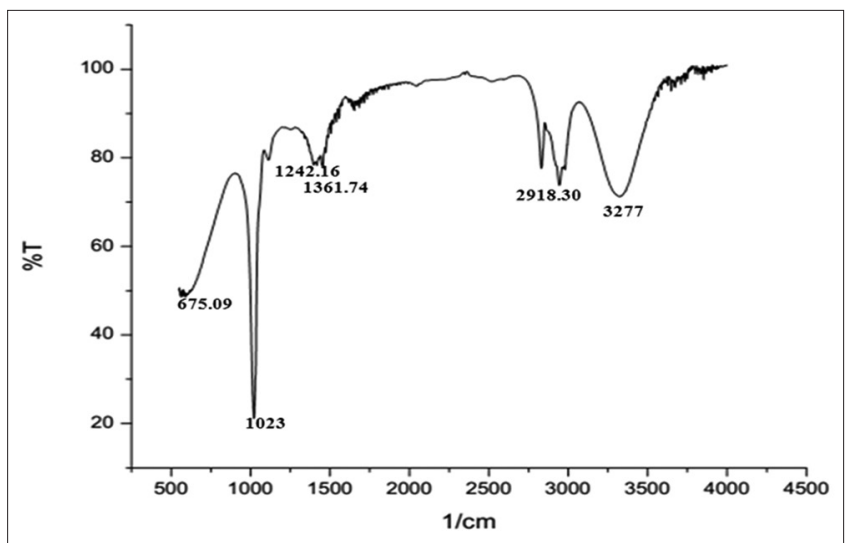

Fig. 6: Fourier transform-infrared analysis of methanolic extract of Cassia fistula leaf

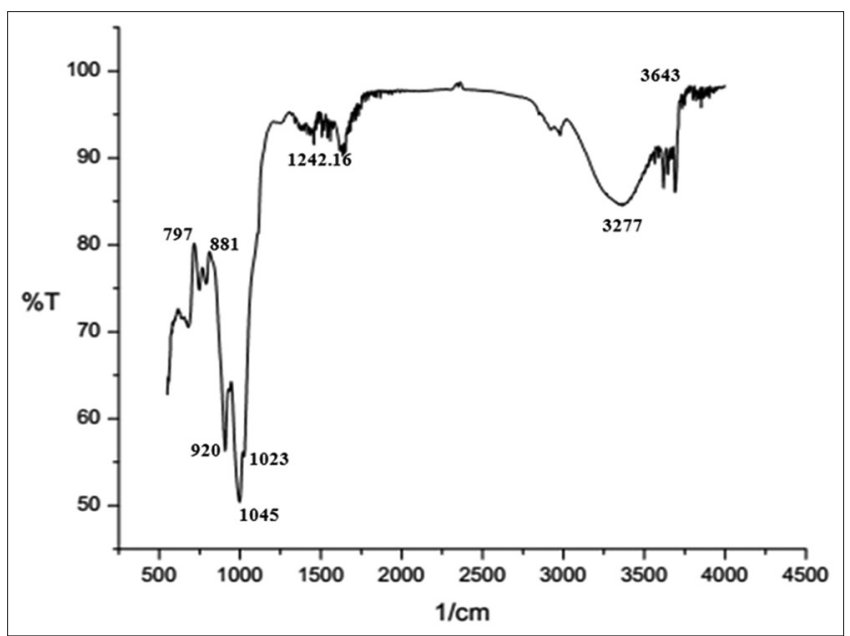

Fig. 7: Fourier transform-infrared analysis for organobentonite

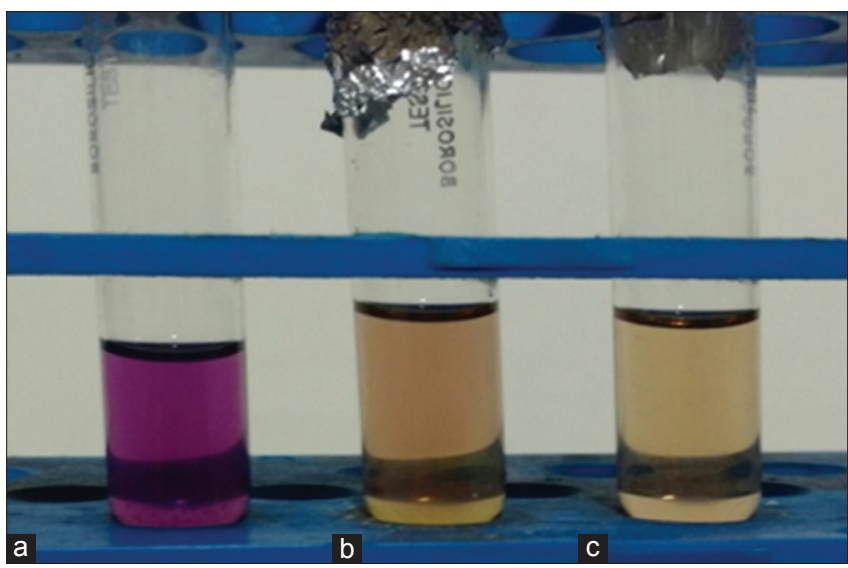

Fig. 8: Antioxidant activity (a) nanoclay, (b) extract, (c) organobentonite 


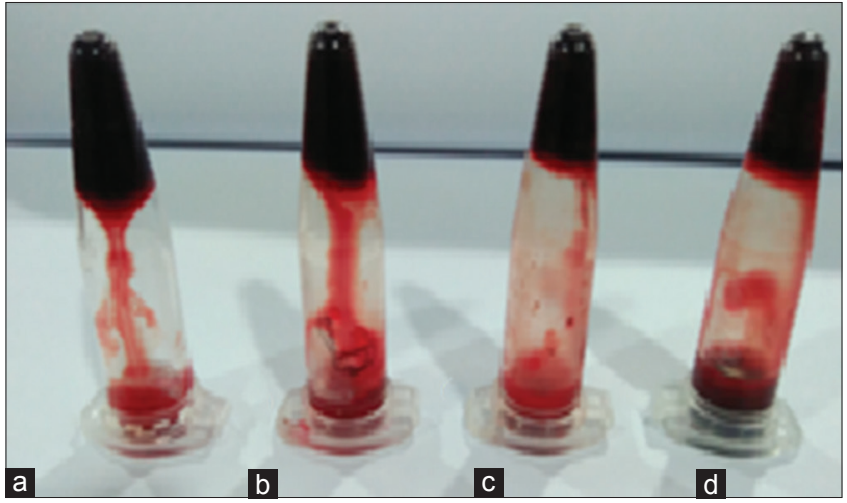

Fig. 9: Clot lysis activity (a) control, (b) nanoclay, (c) extract, (d) organobentonite

$13.795 \%$ of inhibition. The result confirms the antioxidant capacity of the organobentonite.

\section{Clot lysis analysis}

The results obtained through in vitro method reveals about $31 \%$ of clot lysis for the organobentonite, $22 \%$ for the extract, and $16 \%$ for the nanoclay. The control with distilled water has $6 \%$ of clot lysis. Fig. 9 shows the lysis of blood clot after the addition of the samples to the pre-weighed blood clots.

\section{CONCLUSION}

Thus, it was found that the preparation of nanoclay from the natural clay minerals is a simple and inexpensive process. The nanosize of the bentonite and peroxide treatment enables easier intercalation of molecules. The FTIR analysis confirmed the successful incorporation of the methanolic extract within the bentonite nanoclay to form organobentonite. The prepared organobentonite showed good antioxidant and thrombolytic property than the nanoclay or extract.

\section{ACKNOWLEDGMENT}

The authors are grateful to the management of St Joseph's College of Engineering, Chennai, for rendering complete support for the research work completion.

\section{CONFLICTS OF INTEREST}

There are no inherent conflicts of interest in the author's point of view.

\section{AUTHOR'S CONTRIBUTION}

We L.F.A. Anand Raj and J. Jeslin have designed and performed the experiments, analyzed all the data, and prepared the manuscript.

\section{REFERENCES}

1. Zhang D, Zhou C, Lin C, Tong D, Yu W. Synthesis of clay minerals. Appl Clay Sci 2010;50:1-11.
2. Salam MA, Kosa SA, Al-Beladi AA. Application of nanoclay for the adsorptive removal of Orange $\mathrm{G}$ dye from aqueous solution. J Mol Liq 2017;167:3-4.

3. Floody MC, Theng B, Reyes P, Mora M. Natural nanoclays: Applications and future trends-a Chilean perspective. Clay Miner 2009;44:161-76.

4. Apsana G, George PP, Devanna N, Yuvasravana R. Biomimetic synthesis and antibacterial properties of strontium oxide nanoparticles using Ocimum sanctum leaf extract. Asian J Pharm Clin Res 2018;11:384-9.

5. Rajasekar A, Janakiraman V, Govindarajan K. In vitro cytotoxic study of green synthesized gold and silver nanoparticles using Eclipta prostrata (L.) against Ht-29 cell line. Asian J Pharm Clin Res 2016;9:189-93.

6. Jozefaciuk G. Effect of acid and alkali treatments on surface-charge properties of selected minerals. Clays Clay Miner 2002;50:647.

7. Jozefaciuk G, Bowanko G. Effect of acid and alkali treatments on surface areas and adsorption energies of selected minerals. Clays Clay Miner 2002;50:771.

8. Komadel P. Chemically modified smectites. Clay Miner 2003;38:127.

9. Hosterman JW, Patterson SH. Bentonite and Fuller's Earth Resources of the United States. U.S. Geological Survey Professional Paper 1522: United States Government Printing Office; 1992.

10. Venkatathri N. Characterization and catalytic properties of a naturally occurring clay, Bentonite. Bull Catalysis Soc India 2006;5:61-72.

11. Karimi L, Salem A. The role of bentonite particle size distribution on kinetic of cation exchange capacity. J Ind Eng Chem 2010;17:90- 5.

12. Gutierrez TJ, Ponce AG, Alvarez VA. Nano-clays from natural and modified montmorillonite with and without added blueberry extract for active and intelligent food nanopackaging materials. Mater Chem Phys 2017;194:283-92.

13. Duraipandiyan V, Ignacimuthu S. Antibacterial and antifungal activity of Cassiafitula L.:Anethnomedicinal plant.JEthnopharmacol2007;112:590-4.

14. Dutta A, De B. Seasonal variation in the content of sennosides and rhein in leaves and pods of Cassia fistula. Indian J Pharmacol Sci 1998;60:388-90.

15. Panda SK, Padhi LP, Mohanty G. Antibacterial activities and phytochemical analysis of Cassia fitula (Linn.) leaf. J Adv Pharm Technol Res 2011;2:62-7.

16. Govindarajan M. Bioefficacy of Cassia fistula Linn. (Leguminosae) leaf extract against chikungunya vector, Aedes aegypti (Diptera: Culicidae). Eur Rev Med Pharmacol Sci 2009;13:99-103.

17. Floody MC, Bendall JS, Jara AA, Welland ME, Theng BK, Rumpel C, et al. Nanoclays from an andisol: Extraction, properties and carbon stabilization. Geoderma 2011;161:159-67.

18. James O, Adediran M, Adekola F, Odebumni E, Adekeye J. Benefication and characterization of a bentonite from north-eastern Nigerian. J N C Acad Sci 2008;124:154-8

19. Gowdhami M, Sarkar BL, Ayyasamy PM. Screening of phytochemicals and antibacterial activity of Annona squamosa extracts. Int J Pharm Sci Invent 2014;3:30-9.

20. Nooria S, Kokabia M, Hassan ZM. Nanoclay enhanced the mechanical properties of poly (vinyl alcohol)/chitosan/montmorillonite nanocomposite hydrogel as wound dressing. Procedia Mater Sci 2015;11:152-6.

21. Molyneux P. The use of the stable free radical diphenylpicrylhydrazyl (DPPH) for estimating antioxidant activity, Songklanakarin. J Sci Technol 2004;26:211-9.

22. Prasad S, Kashyap RS, Deopujari JY, Purohit HJ, Taori GM, Daginawala HF. Development of an in vitro model to study clot lysis activity of thrombolytic drugs. Thromb J 2006;1477:4-14.

23. Wanyika H, Maina E, Gachanja A, Marika D. Instrumental characterization of montmorillonite clays by X-Ray fluorescence spectroscopy, fourier transform infrared spectroscopy, X-Ray diffraction and UV/visible spectrophotometry. J Agr Sci Technol 2016;17:1 . 